\title{
Description of the Immature Stages of Anopheles (Nyssorhynchus) rondoni (Neiva \& Pinto) (Diptera: Culicidae)
}

\author{
Maria Anice Mureb Sallum/ ${ }^{+}$, Richard C Wilkerson*
}

\begin{abstract}
Núcleo de Pesquisa Taxonômica e Sistemática em Entomologia Médica (NUPTEM), Departamento de Epidemiologia, Faculdade de Saúde Pública, Universidade de São Paulo, Av. Dr. Arnaldo 715, 01246-904

São Paulo, SP, Brasil *Department of Entomology, Walter Reed Army Institute of Research, Washington, DC 20307, USA
\end{abstract}

The larval and pupal stages of Anopheles (Nyssorhynchus) rondoni (Neiva and Pinto) (Albimanus Section) are fully described and illustrated for the first time. The larval stage is similar to An. (Nys.) strodei Root. It can be recognized by the following combination of characters: clypeal index, 1.6-2.9; single, aciculate setae 2,3-C; seta 3-C 0.5-0.7 the length of 2-C; setae 1,2-P rarely sharing a common tubercle; seta 1-P with narrow leaflets. The pupal stage is distinguished from other Nyssorhynchus by having setae 1-IV-VII and 5-V-VII branched. Only minor variation was found in setal counts between specimens from Peixoto de Azevedo, State of Mato Grosso and Bocaina, State of São Paulo, Brazil.

Key words: Anopheles (Nyssorhynchus) rondoni - larva - pupa - description - key characters

Anopheles (Nyssorhynchus) includes many of the vectors of human malaria parasites in Central and South America. The subgenus has been the subject of two recent revisions: Faran (1980), Albimanus Section, and Linthicum (1988), Argyritarsis Section. The four species in the Myzorhynchella Section have not been recently revised (see Peyton et al. 1992). A number of species were not available to Faran (1980) and Linthicum (1988) in all life stages. And, subsequent to these revisions additional information has revealed other taxonomic problems. In the Albimanus Section An. sanctielii Senevet and Abonnenc was incompletely described and then only in the male (Floch \& Abonnenc 1951). The immatures of An. galvaoi Causey, Deane and Deane was described by Deane et al. (1946) from individuals from Amazon region, Brazil. An. konderi Galvão and Damasceno was synonymized without comment by Lane (1953) but should be considered valid based on the male genitalia (EL Peyton, pers. comm.). The adult female and immatures of An. dunhami Causey have not been described. Peyton (1993) considered An. trinkae

Partial support was provided by Fundação de Amparo à Pesquisa do Estado de São Paulo (FAPESP) (grant no. 95/7157-2).

${ }^{+}$Corresponding author. Fax: +55-11-282.1898. E-mail: masallum@spider.usp.br

Received 21 October 1996

Accepted 10 January 1997
Faran synonymous of An. dunhami. However, this species can be separated from An. trinkae based on recent collections from the type locality ( $P$ Lounibos, J Conn, G Fritz, L Hribar, R Wilkerson, pers. comm.). In the Argyritarsis Section An. lanei Galvão and Amaral and An. pictipennis (Philippi) immatures are not well described. The An. albitarsis Lynch-Arribálzaga "complex" has, in addition to An. albitarsis, three other species, An. marajoara Galvão and Damasceno, An. deaneorum Rosa-Freitas and an undescribed species (Wilkerson et al. 1995a,c). A morphological means to separate these species has not yet been found.

Here, we present for the first time descriptions of the larva and pupa of An. (Nys.) rondoni (Neiva and Pinto), of the Albimanus Section. An. rondoni was studied by Wilkerson et al. (1995b). They reported a common variant in the adult which lacked a basal ring on hindtarsomere 3, a character used by Faran (1980). They found instead, that the character that identifies adult of this species is a dark spot on the thorax made up of a large dark prescutellar space contiguous with a concolorous central area on the scutellum (also noted in the original description). They also noted the unusual condition in the pupa of branched setae 1-IV-VII and 5-V-VII, not known in other Nyssorhynchus.

\section{MATERIALS AND METHODS}

Female An. rondoni was collected as reported earlier (Wilkerson et al. 1995b) at Peixoto de Azevedo, State of Mato Grosso, Brazil and by ES Bergo at Bocaina, Rio Jacaré-Pepira, Route 255, 
Km 125, State of São Paulo, Brazil. Females were blood fed and traumatized by removal of a wing to induce oviposition. After eclosion the larvae were reared to the adult stage and fourth instar larval and pupal exuviae were mounted on microscope slides appropriately labeled for association with their respective adults. A portion of each progeny brood was also frozen for molecular studies. Specimens are deposited in the National Museum of Natural History (NMNH), Smithsonian Institution, Washington, DC; U.S. Army Medical Research Unit, Rio de Janeiro; Instituto Oswaldo Cruz, Rio de Janeiro; and Núcleo de Pesquisa Taxonômica e Sistemática em Entomologia Médica, Universidade de São Paulo, São Paulo. The following specimens were used for setal counts and measurements (the number in parentheses represents a single progeny brood, the number following it is an individual member of that progeny): Pupae. BRRio 020 (19)3, (21)-5, (25)-1, (26)-4, (27)-2, (28)-7, (29)-5, (30)-5, (31)-2, (34)-3, (35)-1, (41)-1, (44)-1, (45)2 and (53)-2. Larvae. BRRio 020 (19)-3, (20)-6, (21)-5, (25)-3, (27)-2, (29)-2, -5, (30)-5, (31)-2, (32)-5, (33)-1, (34)-1, (35)-1, (37)-2, (38)-1, (41)1, (44)-1, (45)-2 and BR 548 (26) whole larva. Specimens from the State of São Paulo (see above) were used for comparison.

\section{RESULTS}

Pupa (Fig. 1) - Position and development of setae as figured; range and modal number of branches in Table I. Cephalothorax: weakly pigmented, leg cases darker. Seta 2-CT 2-4-branched, shorter than 1,3-CT; 1,3-CT 1-3 and 2-4-branched respectively; 4,5-CT moderately developed, 4-CT 1-5-branched, 5-CT 2-5-branched; 6-CT 2-4 forked, long; 7-CT 1-4-branched; 10-CT 1-3branched; 11-CT 2-5-branched, equal in length to 10-CT; 12-CT about 1.80 length of 10-CT. Trumpet: angusticorn, without tragus; pinna moderately pigmented, about 4.10 length of meatus $(n=10$ for this and following measurements, except where indicated); meatal cleft basally pointed. Abdomen: length $2.23-2.74 \mathrm{~mm}$ ( mean $=2.49 \mathrm{~mm})$; seta 2-I 35-branched, moderately long; 3 -I single or double, as long as 2-I; 4-I 3-6-branched; 5,6-I single or double, long; 7-I 1-4-branched, about 0.60 length of 6-I; 9-I 1-3-branched, as long as 7-I, shorter than 6-I; 0-II-VII moderately developed, 0-II, IV often with 4 branches, 0 -III often 5-branched, 0-V,VI usually triple, 0-VII 1-4-branched; 1-II,III welldeveloped, with 5-15 and 2-10 branches respectively, 1-IV-VII strong, long, about 1.21 length of segment $(n=9)$ [1-IV 0.97-1.33 $($ mean $=1.18), 1$ V 1.14-1.58 $($ mean $=1.28), 1$-VI 1.05-1.56 $($ mean
$=1.27), 1-\mathrm{VII} 0.93-1.33($ mean $=1.10)$ length of segment]; 2-IV-VII usually single, occasionally double, about 0.40 length of segment; 3-IV 4-8branched, extending to caudal margin of segment, 3-V 3-5 forked, extending slightly beyond caudal margin of segment; 5-III usually with 8 branches, length about half of following segment, 5-IV 1-5branched, median branches longer and stronger than the lateral branches, 5-V usually triple, 5VI,VII usually double, branches unequally developed; 6-II,IV,VI,VII always single, 6-III,V single or double, 6-II about 1.90 length of 7-II $(n=2)$, 7II 2-5-branched, 7-III,V and 8-III-VII moderately short, 7-III 2-5-branched, 7-IV 2-7-branched, 7-V 1-3-branched, 7-VI,VII single or double, long; 8III,IV 1-4-branched, 8-V,VI single or double, 8VII 1-5-branched; 9-II minute, unpigmented, 9-III stout, short, about 1.61 length of 9-II, 9-IV thick, about 2.90 length of 9-III, dark, 9-V strong, about 1.60 length of 9-IV, 9-VI strong, weakly curved, about 1.10 length of 9-V, 9-VII strong, curved, acuminate, about 1.50 length of 9-VI, 9-VIII straight, about 1.10 length of 9-VII, 9-II-VI less than 0.40 length of segment, 9-VII,VIII about 0.5 length of segment; 10-III 1-4-forked, 10-IV,V usually single, long; 4-VIII with 1-4 branches. Genital lobe: heavy, thick at base, with sides sloping toward apex, apex with mamiliform protuberance. Paddle: obovate, 1.24-1.48 $($ mean $=1.36)$ longer than wide; refractile index 0.68-0.78 $($ mean $=0.74)$; outer margin distad of buttress with very fine, filamentous spicules, extending around apex and becoming sparse along caudal 0.5 of inner margin; seta 1-P stronger than 2-P, 2-P 1-3-forked.

No differences were found in the pupal stage when compared to specimens from the State of São Paulo.

Fourth instar larva (Fig. 2) - Position and development of setae as figured; range and modal number of branches in Table II. Head: length 0.56$0.62 \mathrm{~mm}$ (mean $=0.59 \mathrm{~mm})(n=4)$; width 0.54 $0.58 \mathrm{~mm}($ mean $=0.57 \mathrm{~mm})(n=4)$ (measurements of specimens from the State of São Paulo). Integument weakly pigmented with dark spots on posterior region of dorsal apotome and lateralia. Mental plate strongly sclerotized, dark brown to black; median tooth moderately broad, about 1.5 as wide as adjacent tooth, tapered to point, blunt at apex. Seta 2-C single with sparse, small aciculae, 1.521.93 (mean $=1.69)$ length $3-\mathrm{C}$, seta $2-\mathrm{C}$ close to mate of opposite side, distance between bases 0.81$1.82($ mean $=1.31)$ width base of single seta; $3-\mathrm{C}$ single, weakly aciculate $0.52-0.66($ mean $=0.60)$ length 2-C; clypeal index 1.64-2.90 $($ mean $=2.51)$ (distance between bases of $2-\mathrm{C}$ and $3-\mathrm{C}$ on one 

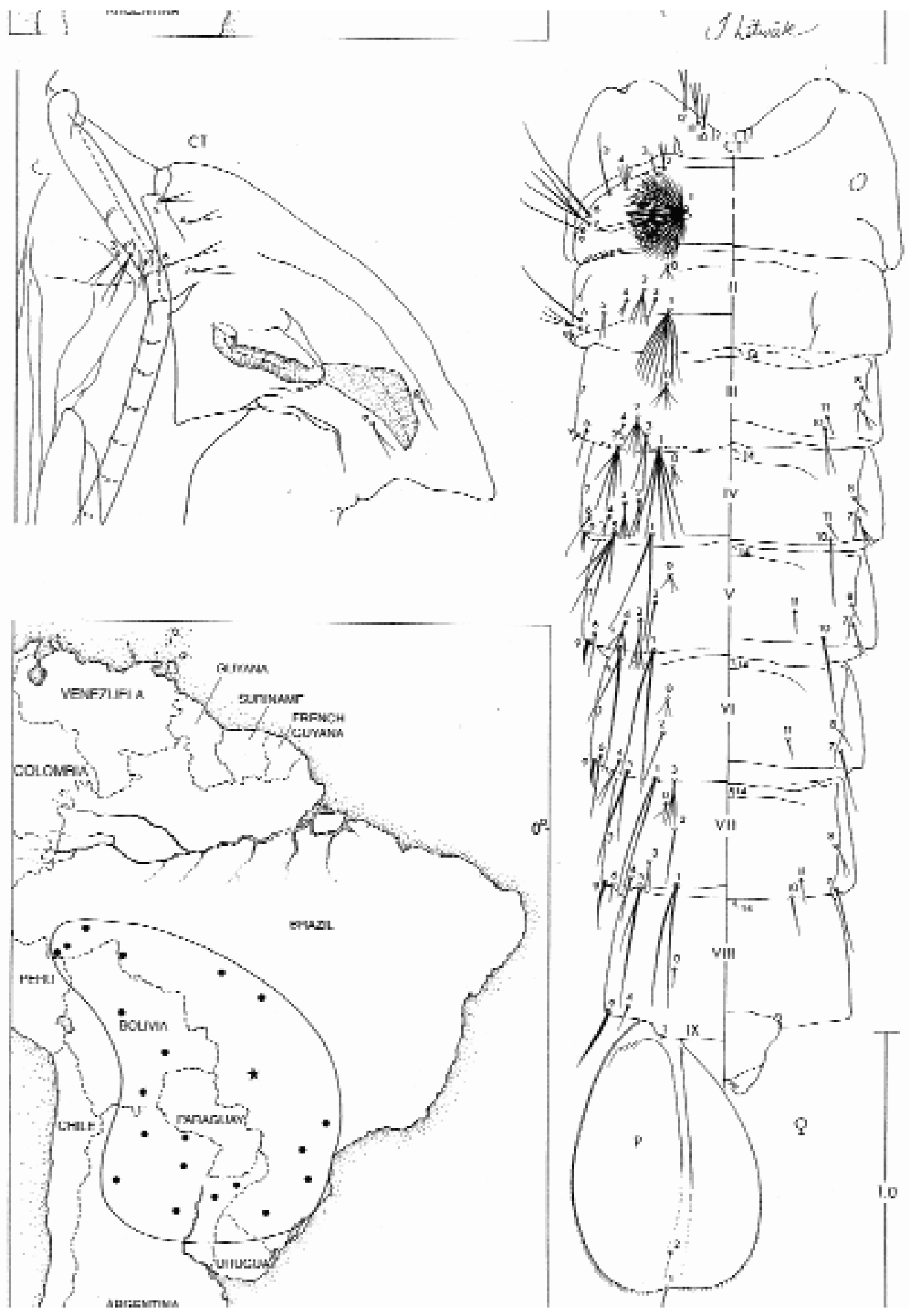

Fig. 1: Anopheles rondoni pupa and distribution map; the star indicates the type locality and the closed circles represent political units in which An. rondoni has been collected. CT: cephalothorax; P: paddle; I-IX: abdominal segments. Scales in mm. 


\section{TABLE I}

Pupal setal branching for Anopheles rondoni: range, mode ( ). Based on counts made from 10 to 20 setae.

When there is more than one mode the highest is shown. A range shown without a mode indicates that the mode was indefinite

\begin{tabular}{|c|c|c|c|c|c|c|c|c|c|c|c|}
\hline \multirow{2}{*}{$\begin{array}{l}\text { Seta } \\
\text { No. }\end{array}$} & \multirow{2}{*}{$\begin{array}{c}\text { Cephalothorax } \\
\text { CT }\end{array}$} & \multicolumn{9}{|c|}{ Abdominal segments } & \multirow{2}{*}{$\begin{array}{c}\text { Paddle } \\
\text { P }\end{array}$} \\
\hline & & I & II & III & IV & $\mathrm{V}$ & VI & VII & VIII & IX & \\
\hline 0 & - & - & $2-6(4)$ & $3-6(5)$ & $3-6(4)$ & $3-5(3)$ & $1-4(3)$ & $1-4(1)$ & 1 & - & - \\
\hline 1 & $1-3(2)$ & $9-15(13)$ & $5-15(6)$ & $2-10(6)$ & $2-5(3)$ & $1-3(2)$ & 2 & $1,2(1)$ & - & - & 1 \\
\hline 2 & $2-4(2)$ & $3-5(6)$ & $4-9(5)$ & $2-7(5)$ & $1,2(1)$ & $1,2(1)$ & $1,2(1)$ & $1,2(1)$ & - & - & $1-3(2)$ \\
\hline 3 & $2-4(3)$ & $1,2(1)$ & 1 & $1-3(1)$ & $4-8(7)$ & $3-5(4)$ & $1-4(2)$ & $2-5(3)$ & - & - & - \\
\hline 4 & $1-5(3)$ & $3-6(6)$ & $2-5(4)$ & $1-6(3)$ & $4-8(7)$ & $2-5(4)$ & $1-3(3)$ & $1-3(2)$ & $1-4$ & - & - \\
\hline 5 & $2-5(4)$ & $1,2(1)$ & $1-3(2)$ & $3-15(8)$ & $1-5(3)$ & $2-4(3)$ & $1-4(2)$ & $1,2(2)$ & - & - & - \\
\hline 6 & $2-4(3)$ & $1,2(1)$ & 1 & $1,2(2)$ & 1 & $1,2(1)$ & 1 & 1 & - & - & - \\
\hline 7 & $1-4(2)$ & $1-4(3)$ & $2-5(4)$ & $2-5(3)$ & $2-7(4)$ & $1-3(3)$ & 1,2 (1) & $1,2(1)$ & - & - & - \\
\hline 8 & 1 & - & 1 & $1-4(3)$ & $1-4(2)$ & $1,2(2)$ & $1,2(1)$ & $1-5(3)$ & - & - & - \\
\hline 9 & $2-4(3)$ & $1-3(1)$ & 1 & 1 & 1 & 1 & 1 & 1 & 1 & - & - \\
\hline 10 & $1-3(1)$ & - & - & $1-4(3)$ & $1,2(1)$ & $1-3(1)$ & alveolus & $1-4(3)$ & - & - & - \\
\hline 11 & $2-5(4)$ & - & - & - & 1 & 1 & 1 & $1,2(1)$ & - & - & - \\
\hline 12 & $1-3(2)$ & - & - & - & - & - & - & - & - & - & - \\
\hline 13 & - & - & - & - & - & - & - & - & - & - & - \\
\hline 14 & - & - & - & 1 & 1 & 1 & 1 & 1 & 1 & - & - \\
\hline
\end{tabular}




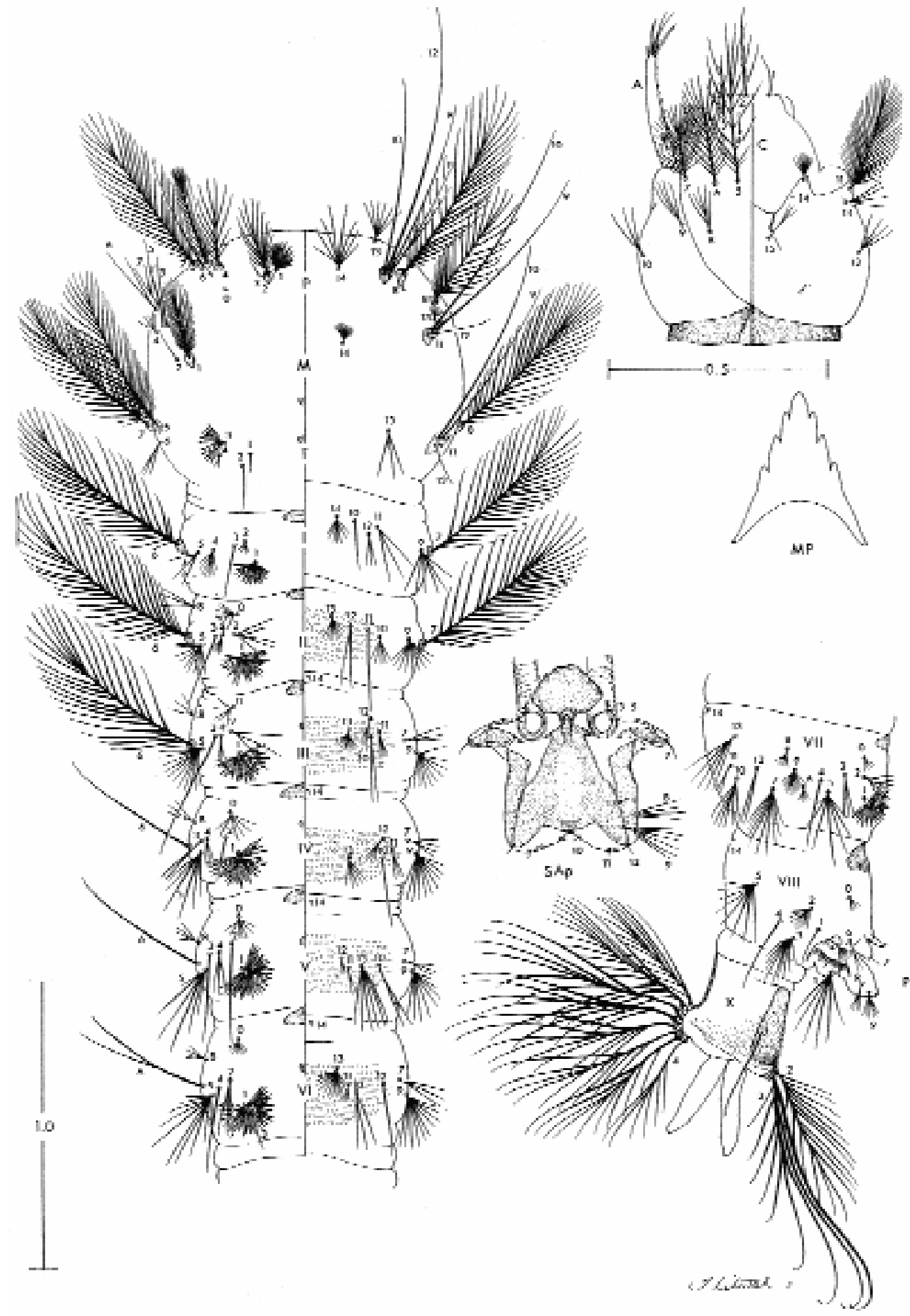

Fig. 2: Anopheles rondoni larva. A: antenna; C: cranium; M: mesothorax; MP: mental plate; P: prothorax; SAp: spiracular apparatus; T: metathorax; I-X: abdominal segments. Scales in $\mathrm{mm}$. 
TABLE II

Larval setal branching for Anopheles rondoni: range, mode ( ). Most based on counts of twenty setae. When there is more than one mode the highest is shown. A range shown without a mode indicates that the mode was indefinite

\begin{tabular}{|c|c|c|c|c|c|c|c|c|c|c|c|c|c|}
\hline \multirow{2}{*}{$\begin{array}{l}\text { Seta } \\
\text { No. }\end{array}$} & \multirow{2}{*}{$\begin{array}{c}\text { Head } \\
\mathrm{C} \\
\end{array}$} & \multicolumn{3}{|c|}{ Thorax } & \multicolumn{9}{|c|}{ Abdominal segments } \\
\hline & & $\mathrm{P}$ & M & $\mathrm{T}$ & I & II & III & IV & $\mathrm{V}$ & VI & VII & VIII & $\mathrm{X}$ \\
\hline 0 & - & 1 & - & - & - & $5-8(6)$ & $5-8(6)$ & $4-8(5)$ & $4-8(6)$ & $4-7(6)$ & $3-7(4)$ & $3-7(4)$ & - \\
\hline 1 & 1 & $10-27(11)$ & $28-38$ & $1,2(1)$ & $11-18(15)$ & $21-29(25)$ & $22-40(32)$ & $23-34(26)$ & $20-29(28)$ & $19-30(25)$ & $20-31(25)$ & 1 & 1 \\
\hline 2 & 1 & $11-19(14)$ & $1,2(1)$ & 1 & $3-5(3)$ & $3-7(5)$ & $3-5(3)$ & 1 & 1 & $2-5(3)$ & $5-9(6)$ & $6-16(12)$ & $16-20(19)$ \\
\hline 3 & 1 & $1,2(1)$ & 1 & $10-18(13)$ & $1-3(1)$ & 1 & 1 & $1-4(3)$ & $1,2(1)$ & 1 & $3,4(3)$ & $8-18(15)$ & $7-10(9)$ \\
\hline 4 & $1,2(1)$ & $9-16(15)$ & $2-5(4)$ & $1-4(3)$ & $3-9(5)$ & $4-6(5)$ & $2-4(3)$ & $2-5(3)$ & $3,5(3)$ & 1 & $1,2(1)$ & 1 & 8 \\
\hline 5 & $14-22(19)$ & $15-34$ & 1 & $15-34$ & $3-5(5)$ & $6-12(5)$ & $8-15(9)$ & $4-9(6)$ & $6-9(7)$ & $6-11(9)$ & $7-13(10)$ & $5-8(7)$ & - \\
\hline 6 & $15-22(17)$ & 1 & $2-5(3)$ & $2,3(3)$ & $24-36$ & $30-37$ & $11-28$ & 1 & $1,2(1)$ & 1 & $4-8(6)$ & $1-S$ & $4-9(6)$ \\
\hline 7 & $16-27(23)$ & 24-39 & $2-4(3)$ & $18-37$ & $26-35$ & $28-36$ & $3-5(4)$ & $3-6(4)$ & $3-5(4)$ & $2-4(3)$ & $6-11(7)$ & $2-S$ & $5-10(8)$ \\
\hline 8 & $2-5(4)$ & $25-35$ & $14-33$ & $29-39$ & - & $2-4(3)$ & $3-6(3)$ & $2-5(3)$ & $3-5(3)$ & $3,4(3)$ & $4-9(6)$ & $6-S$ & $1,2(1)$ \\
\hline 9 & $2-5(3)$ & 1 & 1 & 1 & $5-9(6)$ & $6-15(12)$ & $8-16(12)$ & $7-13(9)$ & $6-15$ & $6-13(10)$ & $5-14(8)$ & $7-S$ & 1 \\
\hline 10 & $1-5(2)$ & 1 & 1 & 1 & $1,2(1)$ & $1-5(4)$ & $1-3(2)$ & $1-2(1)$ & $1,2(2)$ & $2-5(4)$ & $4-8(5)$ & $8-S$ & $4-7(5)$ \\
\hline 11 & $>30$ & $2,3(2)$ & 1 & 1 & $2-4(3)$ & $1-5(2)$ & $2-4(3)$ & $2-4(3)$ & $1-3(3)$ & $2,3(2)$ & $2,3(3)$ & 9-S & $3-11(6)$ \\
\hline 12 & $4-6(5)$ & 1 & 1 & $2-4(2)$ & $2,3(3)$ & $1-3(2)$ & $3-5(4)$ & $3-6(4)$ & $1-3(3)$ & 1 & $1-3(1)$ & - & - \\
\hline 13 & $3-6(4)$ & $4-6(5)$ & $4-9(7)$ & $3-5(3)$ & $5-9(7)$ & $7-13(12)$ & $8-16(11)$ & $4-9(5)$ & $5-7(5)$ & $8-17(13)$ & $4-7(5)$ & - & - \\
\hline 14 & $1-3(1)$ & 6-14(9) & $8-18(12)$ & - & - & - & 1 & 1 & 1 & 1 & 1 & 1 & - \\
\hline 15 & $1-4(2)$ & - & - & - & - & - & - & - & - & - & - & - & - \\
\hline
\end{tabular}


side/distance between the bases of 2-C). Seta 4-C single or double, short, extending half way to anterior margin of head; 8,9-C 2-5-branched; 10,12$\mathrm{C}$ with 1-5 and 4-6 branches respectively; 13-C 36-branched. Collar dark brown, moderately wide to wide dorsomedially. Antenna: length 0.20$0.25 \mathrm{~mm}$ (mean $=0.22 \mathrm{~mm})$, enlarged toward base 6.58-7.91 (mean $=7.15)$ longer than wide; with long and thin spicules on mesal margin, spicules shorter and fewer on ventral surface; seta 1-A 5-7branched, short, about as long as width of antenna at point of insertion, $0.15-0.23$ (mean $=0.21)$ distance from base; seta 2-A with minute spicules on mesal margin. Thorax: setae 1,2-P usually not sharing a common tubercle, 1-P palmate, with 10-27 moderately narrow, pointed, lanceolate leaflets, 2$\mathrm{P}$ with 11-19 branches; 14-P 6-14-branched, large, branches arising from a short shaft, median branches longer than lateral, extending beyond anterior margin of thorax; 1-M strongly plumose, 28-38-branched; 2-T almost reaching caudal margin of thorax; 3-T palmate, with 10-18 moderately long, narrow leaflets. Abdomen: integument with well developed spicules on ventral side of segments II-VI; seta 0-II-VII moderately large, 0-II,III 5-8branched, 0-IV-V 4-8-branched, 0-VI 4-7branched, 0-VII 3-7-branched; 1-I-VII palmate, 1I with 11-18 narrow leaflets, 1-II-VII with dark, moderately narrow, pointed leaflets; 2-II 3-7branched, strongly developed, large, 2-III 3-5branched, more than 1.5 length of leaflets of 1-III and stronger than 2-II, 2-IV single, about 1.2 length of leaflets of 1-IV, 2-V very long, about 3.2 length of leaflets of 1-V; 5-I 3-5-branched, inserted less than 0.1 its length from lateral margin of abdomen; 5-II 6-12-branched; 9-I 5-9-branched, large; 11-I 2-4-branched, large, shorter than 10-I; 13I,II,III with 5-9, 7-13, 8-16 branches respectively, 13-IV 4-9-branched, very large, subequal to 2-V, extending beyond caudal margin of segment, 13VI 8-17-branched, moderately developed. Pecten with 3-6 long, 9-13 short spines; long spines 1.692.18 (mean $=1.88$ ) length of short spines, arrangement of spines variable; lateral arm of median plate of spiracular apparatus short to moderately short, directed dorsolaterally; setae 8,9-S with 4-7, 3-11 branches respectively. Segment $X$ : most of segment covered with fine spicules, spicules stronger on posterior margin; seta $1-\mathrm{X}$ as long as length of saddle, inserted near or on ventral margin of saddle. Anal gills longer than saddle.

A small number of differences in setal counts were found in specimens from the State of São Paulo as follow: seta 4-P 14-21-branched; seta 12M 1,2-branched; seta 12-T 1-3-branched; seta 13T 2-4-branched; seta 11-VII 1,2-branched.

\section{DISCUSSION}

The pupa stage can be incorporated into Faran's (1980) key by the addition of a new couplet number 1, thus displacing all other couplets by a single number as follows:

1 Seta 1-IV 2-5-branched, usually triple, 1-V usually double (1-3), 1-VI always double; seta 5V-VII usually branched (1-4).................rondoni

Seta 1-IV-VII always single; seta 5-V-VII usually single (5-V often double in strodei) ..........2

The larva of An. rondoni cannot be directly incorporated into the most recent key to the Albimanus Section (Faran 1980). A complete reexamination of the larvae of all species would be needed to produce a key that includes An. rondoni, which is beyond the scope of this work. Here we discuss the characters observed in the larva of $A n$. rondoni in relation to those reported by Faran (1980) for the other species. The following measurements and ratios are by nature equivocal since, for the most part, total variation in the subgenus has not been fully studied.

An. albimanus Wiedemann is unambiguously eliminated in the first couplet of Faran's (1980) key. The second couplet uses the clypeal index (distance between setae 2-C and 3-C on one side/ distance between the bases of seta 2-C). An index of 1.0-2.0 (the distance between the bases of seta 2-C is relatively wide) leads to An. triannulatus (Neiva and Pinto) (also unambiguously eliminated), An. benarrochi Gabaldon, Cova Garcia and Lopez, An. aquasalis Curry, An. oswaldoi (Peryassú), An. ininii Senevet and Abonnenc, An. rangeli Galbaldon, Cova Garcia and Lopez, An. trinkae, An. nuneztovari Galbaldon and $A n$. evansae (Brethes); an index of 2.5-4.0 (distance between the bases of 2-C relatively short) leads to An. strodei Root and An. anomalophyllus Komp. An. rondoni is intermediate at 1.6-2.9.

A specimen of An. rondoni with a clypeal index of 1.6-2.0 could be confused with An. evansae or An. rangeli. The other six species either have a distinctly-branched 2,3-C (An. benarrochi, An. aquasalis, An. oswaldoi), not found in An. rondoni, or have a clypeal index of less than 1.3 (An. ininii, An. trinkae, An. nuneztovari). However, both An. evansae and An. rangeli can be separated from $A n$. rondoni since they have seta 3-C greater than 0.8 the length of 2-C. In An. rondoni 3$\mathrm{C}$ is shorter, 0.5-0.7 the length of 2-C.

If the clypeal index is more than 2.5 (an index of 2.0-2.5 could direct one in either direction in the key) then one is lead to An. strodei and An. anomalophyllus. An. anomalophyllus has seta 1,2$\mathrm{P}$ sharing a common tubercle and seta 1-P has mod- 
erately broad to broad leaflets. An. strodei and An. rondoni have 1,2-P rarely sharing a common tubercle and 1-P has narrow leaflets. In other respects An. strodei and An. rondoni are isomorphic in the larval stage and male genitalia. However, based on our observations and on Faran (1980), they can be separated by the clypeal index; 1.6-2.9 for $A n$. rondoni, 3.0-4.0 for An. strodei.

\section{ACKNOWLEDGMENTS}

To Taina $\mathrm{R}$ Litwak for preparation of the figures and to EL Peyton for critical review of the manuscript. Special thanks to Oswaldo P Forattini for support on this research.

\section{REFERENCES}

Deane MP, Causey OR, Deane LM 1946. An illustrated key by larval characteristics for the identification of thirty-two species of Anophelini from the northeast and Amazon regions of Brazil, with descriptions of two larvae. Am J Hyg, Monogr Series 18: 35-50.

Faran ME 1980. Mosquito studies (Diptera: Culicidae). XXXIV. A revision of the Albimanus Section of the subgenus Nyssorhynchus of Anopheles. Contrib Am Entomol Inst (Ann Arbor) 15: 1-215.

Floch H, Abonnenc E 1951. Anopheles de la Guyane Francaise. Inst Pasteur Guyane Territ Inini Arch Publ, 144 pp.

Lane J 1953. Neotropical Culicidae. São Paulo, Univ.
São Paulo. vol. 1, 548 pp.

Linthicum KJ 1988. A revision of the Argyritarsis Section of the subgenus Nyssorhynchus of Anopheles (Diptera: Culicidae). Mosq Syst 20: 99-271.

Peyton EL 1993. Anopheles (Nyssorhynchus) dunhami, resurrected from synonymy with Anopheles nuneztovari and validated as a senior synonym of Anopheles trinkae (Diptera: Culicidae). Mosq Syst 25: 151-156.

Peyton EL, Wilkerson RC, Harbach RE 1992. Comparative analysis of the subgenera Kerteszia and Nyssorhynchus of Anopheles (Diptera: Culicidae). Mosq Syst 24: 51-69.

Wilkerson RC, Gaffigan TV, Lima JB 1995a. Identification of species related to Anopheles (Nyssorhynchus) albitarsis by random amplified polymorphic DNA-polymerase chain reaction (Diptera: Culicidae). Mem Inst Oswaldo Cruz 90: 721-732.

Wilkerson RC, Hribar HJ, Milstrey EG, Calderon FG 1995b. The identification of Anopheles (Nyssorhynchus) rondoni (Diptera: Culicidae) in Mato Grosso State, Brazil: An analysis of key character variability. Mem Inst Oswaldo Cruz 90: 575582.

Wilkerson RC, Parsons TJ, Klein TA, Gaffigan TV, Bergo E, Consolím J 1995c. Diagnosis by random amplified polymorphic DNA polymerase chain reaction of four cryptic species related to Anopheles (Nyssorhynchus) albitarsis (Diptera: Culicidae) from Paraguay, Argentina, and Brazil. J Med Entomol 32: 697-704. 